\title{
ELECTROOXIDATION OF SULFITE AT CARBON PASTE ELECTRODE MODIFIED WITH IONIC LIQUIDS DERIVATED OF N-OCTYL-PYRIDINIUM HEXAFLUOROPHOSPHATE WITH DIFFERENT SUBSTITUENTS IN THE CATION
}

\author{
FRANCESCA FUENZALIDA ${ }^{1,3}$, CAMILO GARCÍA ${ }^{2}$, MACARENA GARCÍA ${ }^{3}$, ROXANA ARCE ${ }^{3}$, CARLA BÁEZ \\ MARÍA JESÚS AGUIRRE ${ }^{3 *}$, MAURICIO ISAACS ${ }^{4}$, MARÍA DEL CARMEN ARÉVALO ${ }^{5 *}$
}

\author{
${ }^{1}$ Universidad de las Américas, Instituto de Ciencias Naturales, Manuel Montt 948, Santiago, Chile. \\ ${ }^{2}$ Universidad Católica de Temuco, Facultad de Recursos Naturales, Escuela de Ciencias Ambientales, \\ Avenida Rudecindo Ortega 02950, Campus San Juan Pablo II, Temuco, Chile. \\ ${ }^{3}$ Universidad de Santiago de Chile, Facultad de Química y Biología, Departamento de Química de los Materiales. \\ Av. L.B. O'Higgins 3363, Estación Central, Santiago, Chile. \\ ${ }^{4}$ Pontificia Universidad Católica de Chile, Facultad de Química, Departamento de Química Inorgánica, \\ Av. Vicuña Mackenna 4860, Santiago, Chile. \\ ${ }^{5}$ Universidad de La Laguna, Facultad de Química, Departamento de Química Física, 38771, \\ La Laguna, Tenerife, España.
}

\begin{abstract}
Carbon paste electrodes modified with a family of ionic liquids (as binders) derived from N-octyl-pyridinium hexafluorophosphate, (composite-ionic liquid electrodes (CILEs)) were studied toward the oxidation of sulfite as an inner-sphere probe reaction and compared to a conventional carbon paste electrode (CPE) in which the binder was mineral oil. The ionic liquids were modified at para-position with substituents that are electron withdrawing: - $\mathrm{CN}$ (CILE/CN) and - $\mathrm{CF}{ }_{3}$ $\left(\mathrm{CILE} / \mathrm{CF}_{3}\right)$ and substituents that are electron donating: $-\mathrm{CH}_{3}\left(\mathrm{CILE} / \mathrm{CH}_{3}\right)$ and $-\mathrm{OCH}_{3}\left(\mathrm{CILE} / \mathrm{OCH}_{3}\right)$, and compared with the ionic liquid without substituents (CILE/OPy). The results showed that CILEs are capable of catalyzing the sulfite oxidation, shifting the oxidation potential to more negative values compared to CPE. Also, they showed linear correlations between increasing sulfite concentration and increasing current density. The best system in terms of sensitivity was the electrode modified with the 4-methyl-N-octylpyridiniumhexafluorophosphate $\mathrm{CILE} / \mathrm{CH}_{3}$ and, then, that modified with the non-substituted ionic liquid CILE/OPy measured by amperometry. In terms of potential, the best systems are the CILEs modified with ILs with inductive-substituents, $-\mathrm{CH}_{3}$ and $-\mathrm{CF}_{3}$ and $\mathrm{OPy}$, indicating that the delocalization of the charge of the cation produced by the mesomeric-substituent $\left(-\mathrm{OCH}_{3},-\mathrm{CN}\right)$ diminishes the electrocatalytic behavior of these binders

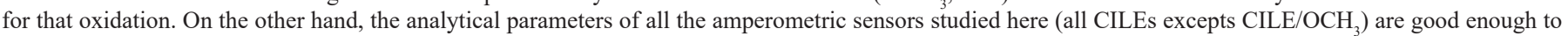
be applied in food industry for samples without polyphenols at concentrations higher than ca. $1 \mathrm{mM}$ of sulfite. Their stability is very high (at least $100 \mathrm{cycles}$ after obtaining a stable response without changing its current, exposed to air and humidity) and they can be used to remove sulfite from wastewaters. Finally, to our knowledge, there are not comparative studies about the effect of changing the substituent of the cation in electrocatalysis of modified IL-electrodes.
\end{abstract}

Keywords: Ionic liquids, N-octyl-pyridinium hexafluorophospate, Composite ionic-liquid electrodes CILEs, Carbon paste electrode CPE, Sulfite oxidation, Effect of the substituent.

\section{INTRODUCTION}

Ionic liquids (IL) are a family of compounds generally defined as molten salts at temperatures below $100^{\circ} \mathrm{C}^{1}$. Now, there are many reports of IL that melt at temperatures higher than $100^{\circ} \mathrm{C}$ but much lower than ionic salts ${ }^{2}$. Their interesting physical and chemical properties are closely dependent of the cation and anion forming the salt ${ }^{3}$. Usually the ionic liquids are composed of organic cations and polyatomic anions, very unsymmetrical and bulky, joined by attractive forces weaker than those of ionic salts. It is possible to modulate the physicochemical properties of ionic liquids depending on the cations or anions of which they are made, becoming very versatile compounds. ${ }^{4}$. The wide variety of combinations of cations and anions allows ionic liquids to have different applications, many of which are important at industry level. One application of these compounds is in electrochemical reactions; they have been used as supporting electrolytes ${ }^{6-7}$ and recently they have been studied to modify glassy carbon electrodes (GC), platinum electrodes, and carbon paste electrodes (CPE). For the CPE it has been determined that ionic liquids could be a good choice as binders ${ }^{8}$ because they produce an increase in the faradic and capacitive currents compared to the classic carbon paste electrode 9 . The increased current is related to the increased electroactive area product of ionic conductivity of these molecules ${ }^{10}$ and due to the high permeability of IL as a hydrophilic binder ${ }^{11}$. Also, IL can be used for modifying electrodes for sensor studies. As an example, glucose-capped CdSe quantum dots and 1-3-ethyl-3methyl-imidazolium:PF ionic liquid incorporated to graphite paste electrodes show good behavior for the determination of minoxidil ${ }^{11}$. On the other hand, glassy carbon covered with platinum-tungsten alloy nanoparticles, reduced graphene, and ionic liquid 1-butyl-3-methyl-imidazolim chloride can sense nitric oxide with a detection limit as low as $0.13 \mathrm{nM}$ and high sensivity and good selectivity ${ }^{12}$. Among ionic liquids widely studied in electrochemical reactions are ionic liquids with pyridinium cation derivatives such as $\mathrm{N}$-octyl- pyridinium hexafluorophosphate $\left(\mathrm{OPyPF}_{6}\right)$, which primarily have been used in the construction of modified carbon paste electrodes ${ }^{13-14}$. In spite of the relevant bibliographic information, to our knowledge there are not comparative studies about the performance of changing the substituent of the cation in electrocatalysis of modified IL-electrodes. For that reason, we chose a common analyte that is present in food-wastewaters, wines and many beverages; sulfite. The electrodes were compared in their behavior as catalysts for the oxidation of sulfite at a fixed $\mathrm{pH}$ in order to observe the effect of ionic liquids as binders and the effect of changing the substituent of the cation in the potential where the reaction occurs. Sulfite was chosen because is very used as antiseptic and antioxidant to prevent oxidative decomposition of many foods and beverages. In larger amounts than recommended, sulfite, as a generic term $\left(\mathrm{HSO}_{3}^{-}, \mathrm{SO}_{3}^{-2}\right)$, can alter the organoleptic properties of food and beverages-and people sensitive to this compound can suffer asthma attacks ${ }^{15-16}$. Moreover, a low concentration can allow degradation reactions in food and wine ${ }^{17}$. For that reason, efforts to develop electrochemical methods are being made because they are usually short-time demanding and cheap. In this sense, diverse electrodes were used. For example Y.Yang et al reported a polyaniline-coated cooper hexacyanoferrate modified glassy carbon electrode as sulfite sensor ${ }^{18}$. This electrode has a $0.6 \mu \mathrm{M}$ detection limit and a strong anti-interference ability. On the other hand, carbon paste electrodes modified with carbon nanotubes ${ }^{19}$ were used for voltammetric detection of sulfite in commercial beverages with a limit of detection of $1.0 \mathrm{mg} \mathrm{SO}_{2} \mathrm{~L}^{-1}$. On the other hand, glassy carbon electrodes modified with switching structures of praseodynium hexacyanoferrate show very good electrocatalytic behavior toward the oxidation of sulfite ${ }^{20}$. In spite of its relatively high limit of detection $(2.15 \mu \mathrm{M})$, the electrode, using standard addition, can measure sulfite in real samples of red wine ${ }^{20}$ Also, the behavior of a carbon black paste electrode without modification made from carbon black powder and paraffin oil for detecting sulfite in rice wines was reported ${ }^{21}$. This electrode was applied to measure sulfite by square wave voltammetry in which 
the first derivative was measured in order to obtain a sharp and better-defined signal. Using this method, the detection limit was $6.0 \mu \mathrm{M}$ and can be applied in rice wine samples. On the other hand, a biosensor for sulfite was reported by Sroysee et $\mathrm{al}^{22}$. In this work, the sulfite oxidase inmmobilized on a magnetitegold-folate nanocomposite modified carbon-paste electrode was employed using a flow cell and measuring $\mathrm{H}_{2} \mathrm{O}_{2}$ that corresponds to the product of the reaction of the enzyme and sulfite. In this case, amperometric measures permit to detect sulfite with a limit of detection of $10 \mu \mathrm{M}$. These few examples show the interest that exists to detect sulfite because of its importance in food and beverage industries.

In this work the oxidation of sulfite on modified electrodes was studied with five ionic liquids derived from $\mathrm{N}$-octyl-pyridinium hexafluorophosphate (OPy): 4-methyl-N-octyl-pyridinium hexafluorophosphate $\left(\mathrm{CH}_{3}\right)$, 4-methoxy$\mathrm{N}$-octyl-pyridinium hexafluorophosphate $\left(\mathrm{OCH}_{3}\right)$, 4-cyano-N-octylpyridinium hexafluorophosphate $(\mathrm{CN})$, 4-trifluoromethyl-N-octyl-pyridinium hexafluorophosphate $\left(\mathrm{CF}_{3}\right)$ (see scheme 1), and the IL without substituent $\mathrm{N}$ octyl-pyridinium hexafluorophosphate (OPy) at $\mathrm{pH} 7.4$ to determine the effect of the electron donating or withdrawing substituent on the electrocatalysis. This $\mathrm{pH}$ was selected because of the good response of all the electrodes compared here.

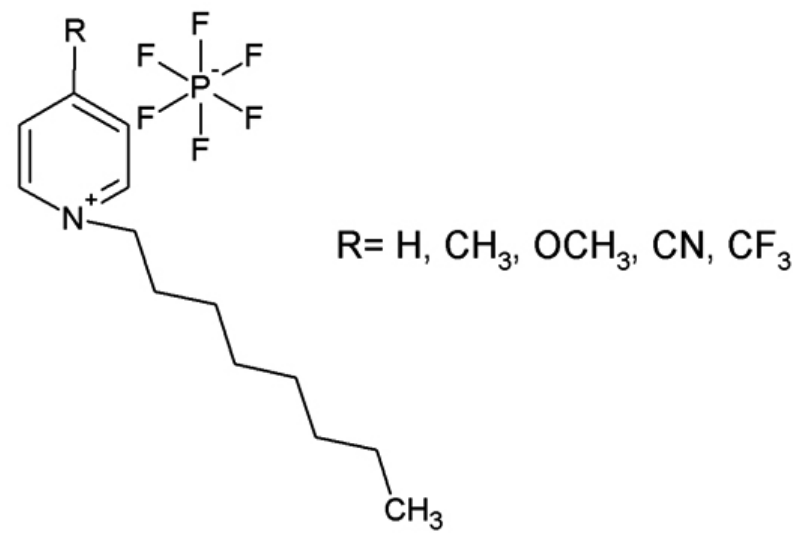

Scheme 1: Ionic liquids used in this work.

\section{EXPERIMENTAL}

Instrumentation

Voltammetric measurements were carried out with $\mathrm{CH} 900 \mathrm{~B}$ and $\mathrm{CH} 604 \mathrm{C}$ Instrument potentiostats connected to $\mathrm{PCs}$ that have $\mathrm{CH}$ Instruments software 900B and 604C respectively. Also, a three electrode-compartment glass cell, Teflon tubes of $2 \mathrm{~mm}$ of diameter with a metal connection for making working electrodes (Teflon hollow electrodes YMA), reference electrode $\mathrm{CH}$ Instrumen $(\mathrm{Ag} / \mathrm{AgCl},+0.22 \mathrm{~V}$ versus $\mathrm{KCl}($ sat)), and $\mathrm{Pt} \mathrm{CH}$ Instrument counter electrode were used.

Reagents and Solvents

All reagents were of analytical grade. For preparing carbon paste electrode, graphite powder of particle size $<50 \mu \mathrm{m}$ (Merck) and mineral oil (Sigma-Aldrich) were used. For preparing phosphate buffer saline solution (PBS) pH 7.4, monobasic potassium phosphate, sodium chloride, potassium chloride (JT Baker), and sodium hydrogenphosphate (VETEC fine chemical) with deionized double distilled water were used. For preparing sulfite solution, sodium sulfite (Merck) was used with deionized double distilled water. Ionic liquids N-octyl-pyridinium hexafluorophosphate (OPy), 4-methyl-N-octyl-pyridinium hexafluorophosphate $\left(\mathrm{CH}_{3}\right)$, 4-methoxy-Noctyl-pyridinium hexafluorophosphate $\left(\mathrm{OCH}_{3}\right)$, 4-cyano-N-octyl-pyridinium hexafluorophosphate $(\mathrm{CN})$, and 4-trifluoromethyl-N-octyl-pyridinium hexafluorophosphate $\left(\mathrm{CF}_{3}\right)$ were synthesized following protocols described in references ${ }^{23-24}$.

Experimental procedure

1. Preparation of CPE and CILEs electrodes. The CPE electrodes were prepared using a homogeneous mixture of high purity graphite powder and mineral oil as binder in a 70:30 mass rate. For the preparation of CILEs electrodes, different ionic liquids were used as binders to replace mineral oil in the same 70:30 mass rate. The paste obtained was added to a Teflon hollow electrode and compacted, and subsequently it was polished on a weighing paper to a smooth surface.

2. Electrochemical characterization of CPE and CILEs electrodes in PBS solution. Electrochemical characterization was carried out by cyclic voltammetry for CPE and CILEs electrodes. Limit potentials from $0.0 \mathrm{~V}$ to $1.0 \mathrm{~V}$ at a scan rate of $0.1 \mathrm{~V} / \mathrm{s}$ in the solution previously purged with $\mathrm{N}_{2}$ for 15 minutes in the electrochemical cell were used.

3. Electrochemical sulfite oxidation. Electrochemical sulfite oxidation was carried out by cyclic voltammetry for CPE and CILEs electrodes. Sulfite solutions were prepared at concentrations, 1, 2, 3, 4, and $5 \mathrm{mM}$ in PBS solutions at different $\mathrm{pHs}$ (ranging from 2 to 11 ) adding drops of $\mathrm{HCl}$ or $\mathrm{NaOH}$ concentrated solutions. At $\mathrm{pH}$ 7.4, PBS solutions have not acid or base added. Limit potentials ranged from $0.0 \mathrm{~V}$ to $1.0 \mathrm{~V}$ at a scan rate of $0.1 \mathrm{~V} / \mathrm{s}$.

4. Amperometric measurements. For amperometric measurements, a standard sulfite solution $0.1 \mathrm{M}$ of PBS $\mathrm{pH} 7.4$ was used. In the cell containing $20 \mathrm{~mL}$ of solution, sulfite aliquots of $50 \mu \mathrm{L}$ every $100 \mathrm{~s}$ were added for a total time of $600 \mathrm{~s}$ and measurements were performed at a potential of $0.45 \mathrm{~V}$.

\section{RESULTS AND DISCUSSION}

1. Electrocatalysis of sulfite oxidation with CILEs electrodes

All the CILEs and CPE were proved toward the oxidation of sulfite at acid, neutral, and basic pHs. At pHs lower than $\mathrm{pH} 3.5$, the species $\mathrm{SO}_{2}$ is generated and is volatilized from the sample when it is bubbled with $\mathrm{N}_{2}$ (see Scheme 2). At pHs more basic than 8 , the response of current in all the electrodes is lowered. At pHs close to 3.5, the response of the electrodes shows a slight increase in current without a clear peak (not shown). At neutral $\mathrm{pH}$, the response in current is better for all the systems. For that reason, $\mathrm{pH} 7.4$ was selected to compare the behavior of the CILEs and CPE. It is important to notice that at this $\mathrm{pH}$ sulfite is present in practically equal concentrations as $\mathrm{HSO}_{3}{ }^{-}$and $\mathrm{SO}_{3}{ }^{2-16}$. The electrodes sense both analytes in only one signal indicating that, in the case of bisulfite, the species is deprotoned when positive potentials are applied as the first step in this oxidation. Electrodes do not discriminate between sulfite and bisulfite. This effect can be measured when the solution is drastically acidified $(\mathrm{pH}<$ 1) and all sulfite and bisulfite is converted in $\mathrm{SO}$. If all this $\mathrm{SO}$ is extracted from the solution trough a membrane in contact with a solution containing $0.02 \mathrm{M} \mathrm{NaOH}(\mathrm{pH}>12)$, all the $\mathrm{SO}_{2}$ is converted in $\mathrm{SO}_{3}{ }^{2-}$. When the charge of the current corresponding to this $\mathrm{SO}^{2-}$ is measured, it corresponds to the charge of the peak observed at $\mathrm{pH} 7.4$, indicating that at $\mathrm{pH} 7.4$ all the species sulfite and bisulfite oxidize at the same potential (not shown). This kind of measurements was done by our group with other modified electrodes ${ }^{25-27}$ and with CILEs and CPE, showing in all the cases that these electrodes do not discriminate between both species. It is interesting to mention here that the absorber system containing the solution $0.02 \mathrm{M} \mathrm{NaOH}$ previously reported by our group ${ }^{25-27}$ allows to measure sulfite and bisulfite in the presence of phenols that are oxidized at practically the same potentials. In this work we determined the behavior of the CILEs and CPE in the presence of sulfite and we studied as possible interfering, gallic acid and rutine. We obtained oxidation waves at the potentials were the sulfite is oxidized (not shown). These polyphenols and others were oxidized at potentials close to gallic acid and rutine will act as interfering if the absorber membrane system is not used.

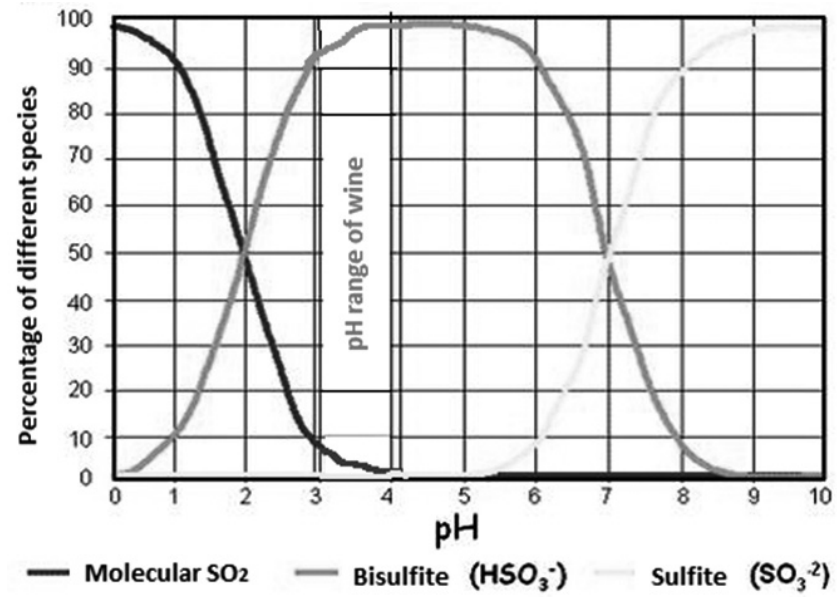

Scheme 2: Speciation diagram of sulfite at different $\mathrm{pH}^{16}$ 
The voltammetric profile of sulfite oxidation using CILE/OPy (Figure 1A) shows that this electrode is active toward the oxidation of sulfite with an oxidation potential peak close to $0.40 \mathrm{~V}$, showing a strong decrease in the overpotential compared to CPE (close to $500 \mathrm{mV}$ ). The increase in current with increasing concentration of this analyte indicates that this electrode has a possible behavior as amperometric sensor. The voltammetric profile of sulfite oxidation with CPE electrode (Figure 1B) shows that this electrode is active toward the oxidation of sulfite at a potential near $0.9 \mathrm{~V}$, showing also an increase of the current density when the concentration of the analyte increases. Voltammetric profiles of $\mathrm{CILE} / \mathrm{CH}_{3}$ and $\mathrm{CILE} / \mathrm{OCH}$, electrodes (Figure 2) show the electron-donating substituents of the cation of the ionic liquid effect in the oxidation behavior. CILEs with electron-donating substituents have a very large capacitive response that makes it difficult to obtain a clear signal for the oxidation of sulfite. For $\mathrm{CILE} / \mathrm{CH}_{3}$, the analyte oxidation is promoted and the peak potential is observed at ca. $0.40 \mathrm{~V}$ (very similar to the oxidation potential peak of the CILE/OPy) in addition to an increase in current density as the concentration increases. Also $\mathrm{CILE} / \mathrm{OCH}_{3}$ shows that it is active toward sulfite oxidation, however the oxidation is poorly defined because this electrode has a considerable resistivity in addition to its high capacitive response. In spite of this poorly defined wave, it is possible to determine that the peak potential appears at ca. $0.5-0.6 \mathrm{~V}$. Furthermore, in the case of electrodes with electronwithdrawing substituents, $\mathrm{CILE} / \mathrm{CN}$ and $\mathrm{CILE} / \mathrm{CF}_{3}$ (Figure 3), it is shown that both are electroactive and present a possible amperometric sensor behavior. Sulfite oxidation potential mediated by CILE/CN is observed at 0.5 to $0.6 \mathrm{~V}$, in contrast to the behavior of CILE/CF 3 where the peak potential is observed at $0.4 \mathrm{~V}$ (very similar to CILE/OPy and CILE/CH ) $_{3}$. In general, the effect of changing the binder (from mineral oil to ionic liquids) can be observed in the shifting of the potential peak compared to CPE, showing that any electrode modified with ionic liquid is more active than conventional carbon paste electrode in spite of the electron donating or withdrawing characteristics. There is a possible effect of increasing the conductivity of the surface when ionic liquids are acting as binders compared to the isolating and hydrophobic effects of mineral oil. However, the main effect of the electron-donating substituents is observed in the high capacitive and more resistive response of the voltammetric response of the CILEs. It is interesting that electrodes with this resistive response have a high catalytic effect indicating a real catalytic effect of the ionic liquid and not only a change in the conductivity of the electrode. This real electrocatalytic effect is clearly noticeable in the different changes in the potential where the reaction takes place. There is not a common shift in the potential when the mineral oil is changed for ILs in the electrodes. Each IL has its own potential shifting showing a different catalytic effect. On the other hand, a porous electrode such as carbon paste ${ }^{17}$ is made of a mixture of conductive graphite powder with a non-electroactive chemically inert binder. In general, the presence of this binder on the surface slows electron transfer and thus the reaction occurs at a higher potential, because the electrode is less conductive. The hydrophobic character of the binder hinders access of hydrophilic analytes to the active electrode surface. Here, sulfite oxidation is shifted toward positive potentials compared to electrodes having an ionic liquid as binder, showing that in the first case (CPE) there is an increase in the energy required for electron transfer. Ionic liquids used as binders act in two ways in the oxidation reaction of sulfite. One is to increase the conductivity of the electrode, and the other is acting as catalysts, i.e. as active sites in oxidation. However, there is a not clear effect on the chemical nature of the substituents and their catalytic behavior to this oxidation. In fact, $\mathrm{CILE} / \mathrm{CH}_{3}, \mathrm{CILE} / \mathrm{CF}_{3}$, and CILE/OPy present a peak potential at ca. $0.4 \mathrm{~V}$ in contrast to CILE/CN and $\mathrm{CILE} / \mathrm{OCH}_{3}$ that present peaks at $0.5-0.6 \mathrm{~V}$ and $\mathrm{CPE}$ at ca. $0.9 \mathrm{~V}$. It was mentioned above that the nature of the CILEs changes with the substituents. In fact, electron-donating substituents-CILEs present a higher capacitive response and a more resistive profile than CILE/OPy, CILE/CN, and CILE/CF . This behavior is not reflected in the potential peak of the oxidation of sulfite.

On the other hand, the polarizability of the cation can be indirectly measured by comparing the melting points of the ILs (see Table 1). From data of Table 1, it is clear that the most polarized cations are those with electronwithdrawing substituents because of their high melting points. However, there is no correlation between the polarization of the cation and the potential required for the oxidation of sulfite. Then a possible explanation for the behavior observed in the potentials required for the oxidation of sulfite is related to the formation of an active site formed by the cation of the ionic liquid that interacts with sulfite species. The positive charge of the ionic liquid is delocalized in the ring of the cation and there are many hydrogen bonds formed with the anion that "protects" the positive charge for interacting with the negatively charged analyte. In this sense, a weak interaction of the cation with the sulfite is proposed. In spite of this weak interaction, the aromatic ring is capable of accepting negative charge from the sulfite oxidizing the species due to its aromatic nature. However, a more stable "delocalized positive charge" would need more energy for accepting an electron compared to a less delocalized cation where the interaction between sulfite and the cation is stronger. In this sense, a mesomeric substituent as $-\mathrm{OCH}_{3}$ or $-\mathrm{CN}$ can delocalize the positive charge in all the space concerning the ring and the substituent. The inductive substituents only allow a delocalization in the ring. For that reason, inductive substituents-IL and the IL without substituent require less energy to oxidize the sulfite species compared to mesomeric substituents-IL. However, more study is necessary in order to prove this hypothesis.

In terms of potential, the most active are CILE/OPy, $\mathrm{CILE} / \mathrm{CH}_{3}$, and CILE/ $\mathrm{CF}_{3}$ and the less active are CILE/CN and CILE/OCH

Table 1. Melting points of ionic liquids.

\begin{tabular}{|c|c|}
\hline Ionic Liquid & Melting point $\left({ }^{\circ} \mathbf{C}\right)$ \\
\hline $\mathbf{O P y}$ & 66 \\
\hline $\mathbf{C H}_{3}$ & 49 \\
\hline $\mathbf{O C H}_{3}$ & 43 \\
\hline $\mathbf{C N}$ & 137 \\
\hline $\mathbf{C F}_{3}$ & 208 \\
\hline
\end{tabular}

A

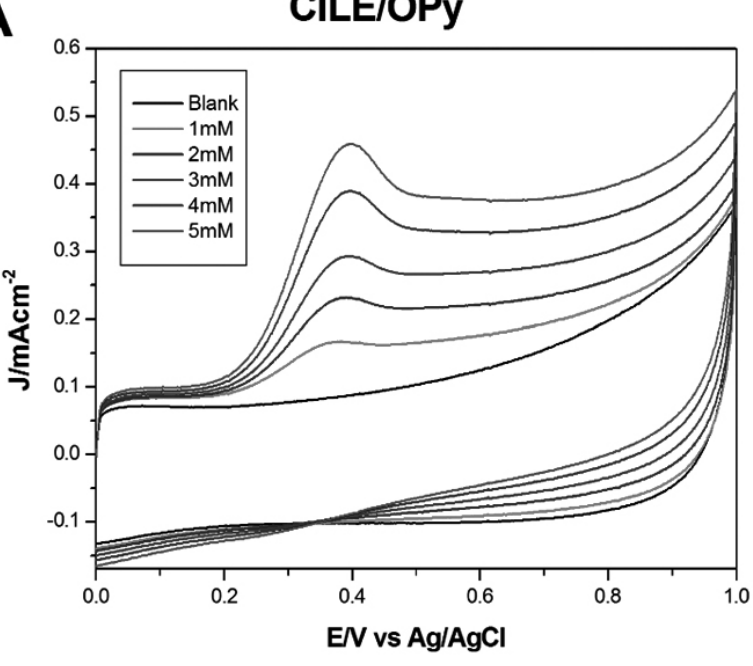

\section{CPE}

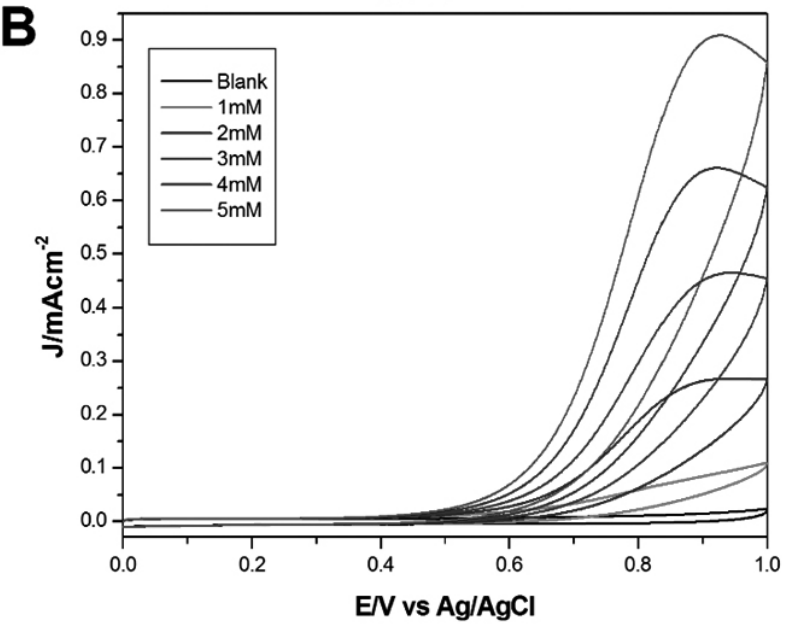

Figure 1. Voltammetric profiles of sulfite oxidation at different concentrations with electrodes A) CILE/OPy B) CPE in PBS solution $\mathrm{pH} 7.4$ to $0.1 \mathrm{~V} / \mathrm{s}$. 


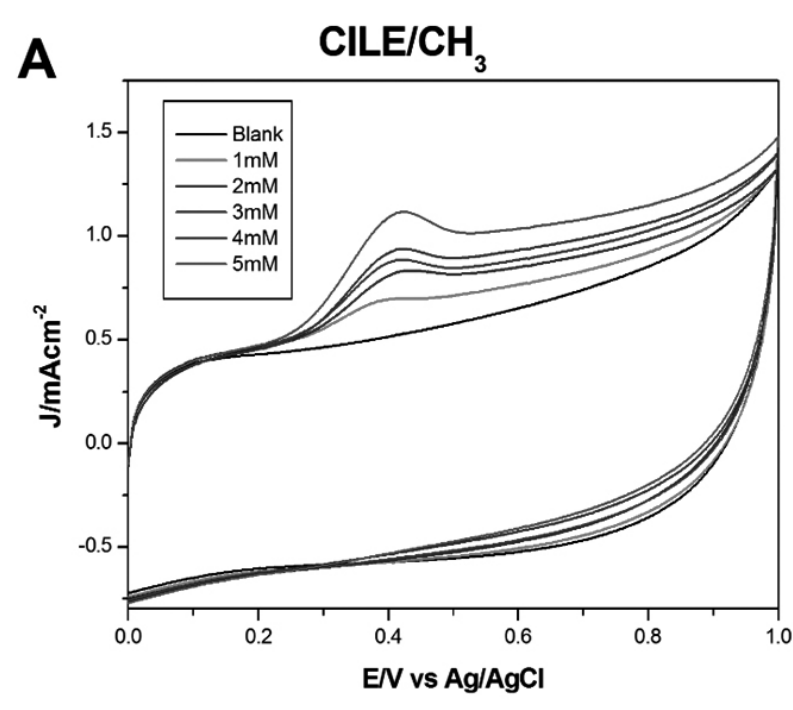

B

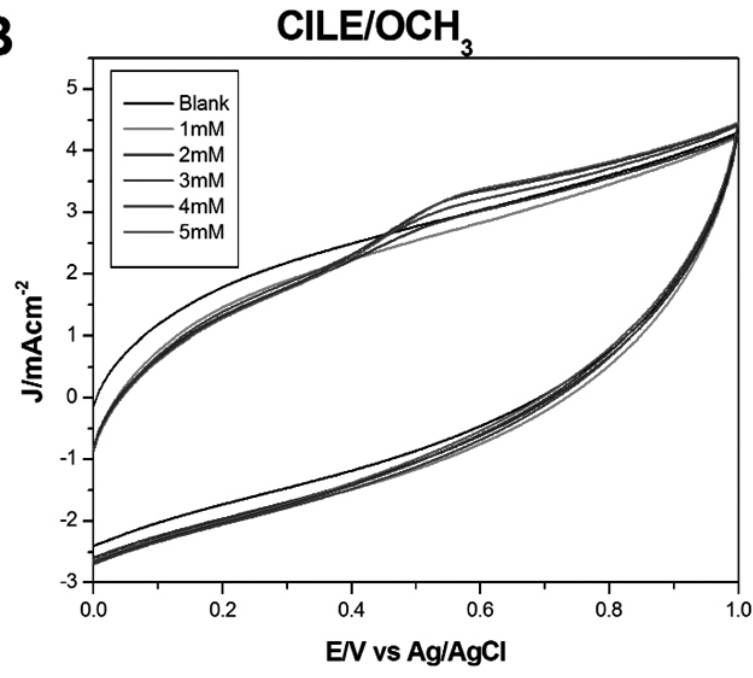

Figure 2. Voltammetric profiles of sulfite oxidation at different concentrations with electrodes A) $\left.\mathrm{CILE} / \mathrm{CH}_{3} \mathrm{~B}\right) \mathrm{CILE} / \mathrm{OCH}_{3}$ in $\mathrm{PBS}$ solution $\mathrm{pH} 7.4$ to $0.1 \mathrm{~V} / \mathrm{s}$.

\section{Amperometric study of sulfite oxidation}

The amperometric study was carried out for CPE and CILEs electrodes. Results show that for all CILEs except CILE/ $\mathrm{OCH}_{3}$ there was an increasing amperometric signal with the increasing concentration of sulfite, as observed in Figure 4A. Subsequently, plots of J vs C show a linear correlation, indicating that these electrodes could be used as sulfite amperometric sensors (Figure 4B). The current densities registered with the electrode $\mathrm{CPE}$ are on the order of $10^{-9} \mathrm{~A}$. This signal is very low (close to the noise) so it is discarded for amperometric uses. On the contrary, CILEs show an increase in current density (at much higher values than $\mathrm{CPE}$ ) with increasing sulfite concentration with linear correlations. In Figure 4B the slope values (see Table 2) correspond to the sensitivity of the electrode. In addition, using this parameter with the standard deviation $(\sigma)$ of the calibration curve, the detection and quantification limits of each electrode can be calculated ${ }^{28}$ (see eq.1).

$$
\frac{3 \sigma}{\text { slope }}=\text { detection limit } \quad \frac{10 \sigma}{\text { slope }}=\text { quantification limit }
$$

eq. 1

Values obtained from the slopes (sensitivity) and limits of detection and quantification $^{28}$ are summarized in Table 2. Linear amperometric responses are obtained using CILEs. CILE/CF ${ }_{3}$ and $\mathrm{CILE} / \mathrm{CN}$ show smaller slopes compared to $\mathrm{CILE} / \mathrm{CH}_{3}$ and CILE/OPy indicating that the CILE/CH 3 and CILE/OPy are better for detecting sulfite because its higher sensibility. For all the CILEs excepting $\mathrm{CILE} / \mathrm{OCH}$ the detection limits are in the range of $1 \times 10^{-4} \mathrm{M}$ allowing their application in analysis of sulfites in pretreated wines and vinegars according to the limits indicated by the Chilean standard that are $2 \mathrm{X} 10^{-3} \mathrm{M}$ for total sulfite and $8 \times 10^{-4}$ for free sulfite ${ }^{29}$.

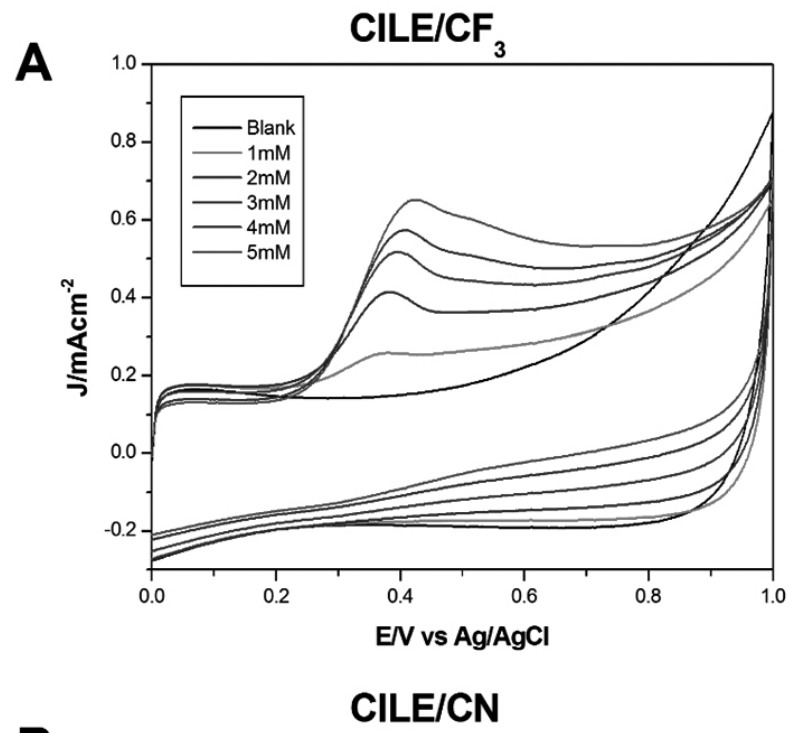

B

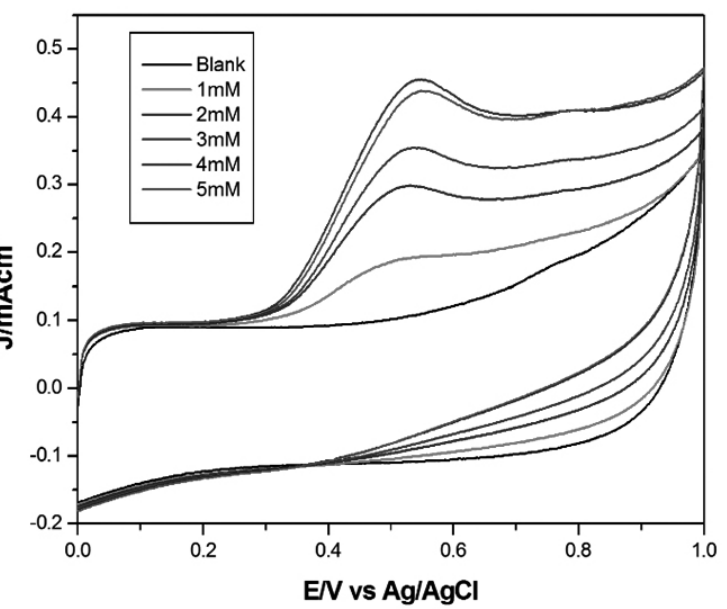

Figure 3. Voltammetric profiles of sulfite oxidation at differen concentrations with electrodes A) $\left.\mathrm{CILE} / \mathrm{CF}_{3} \mathrm{~B}\right) \mathrm{CILE} / \mathrm{CN}$ in $\mathrm{PBS}$ solution $\mathrm{pH}$ 7.4 to $0.1 \mathrm{~V} / \mathrm{s}$

Table 2. Limit of detection and analytical sensitivity for CILEs electrodes.

\begin{tabular}{|c|c|c|c|}
\hline & $\begin{array}{c}\text { Limit of } \\
\text { detection } \\
(\mathbf{m M})\end{array}$ & $\begin{array}{c}\text { Analytical sensitivity } \\
\text { (J/mM) } \\
\text { (slopes of Figure 4B) }\end{array}$ & $\begin{array}{c}\text { Limit of } \\
\text { Quantification } \\
\text { (mM) }\end{array}$ \\
\hline CPE & - & - & - \\
\hline CILE/OPy & 0.107 & 7.9 & 0.35 \\
\hline CILE/CN & 0.355 & 4.3 & 1.18 \\
\hline CILE/CH & 0.129 & 19.5 & 0.43 \\
\hline CILE/OCH & - & - & 0.91 \\
\hline CILE/CF & 0.273 & 1.4 & - \\
\hline
\end{tabular}



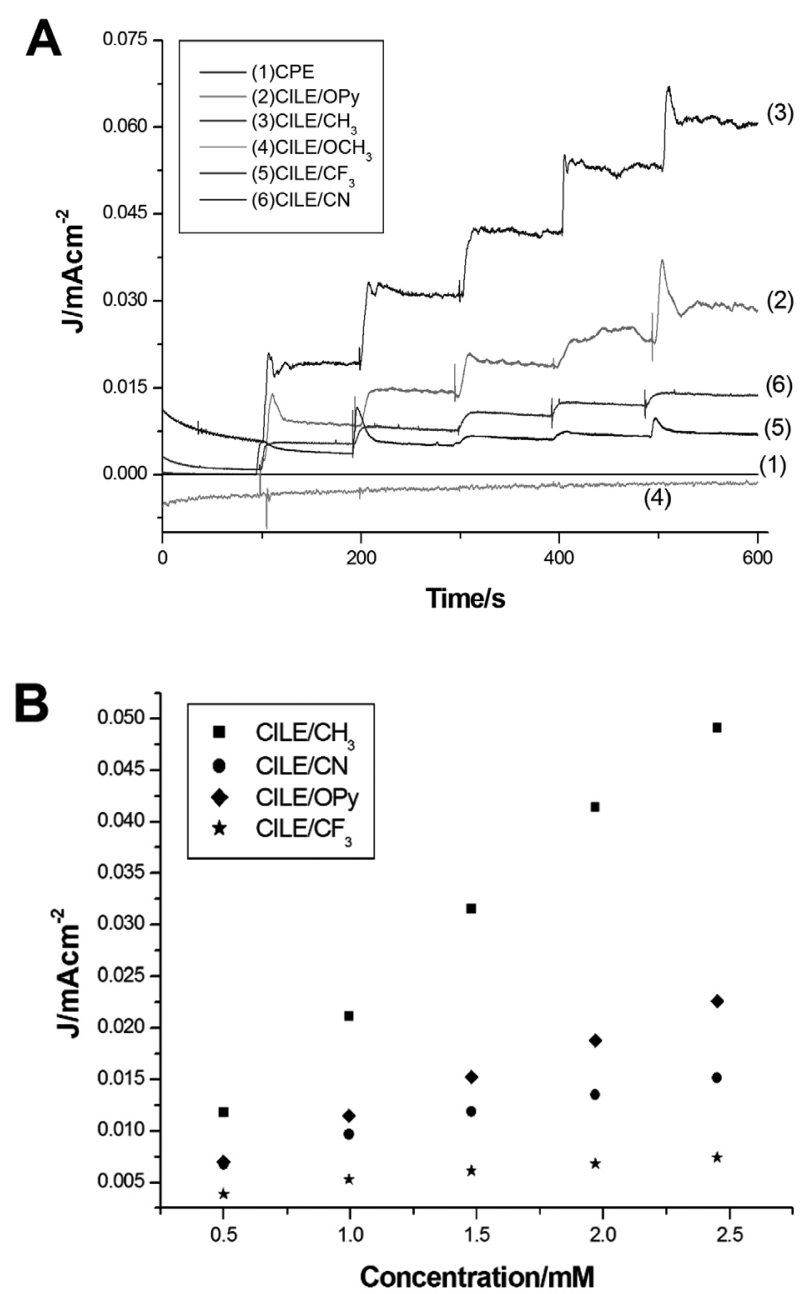

Figure 4. A) J versus t graph comparison for CPE and CILEs electrodes, adding $50 \mu \mathrm{L}$ aliquots of $1 \times 10^{-3} \mathrm{M}$ sulfite solution. B) $\mathrm{J}$ versus $\mathrm{C}$ plots for comparative CILE/OPy, CILE/CN, CILE/ $\mathrm{CH}_{3}$, and CILE/ $\mathrm{CF}_{3}$.

Study of Gallic Acid and Rutine as interferents.

All the CILEs including $\left(\mathrm{CILE} / \mathrm{OCH}_{3}\right)$ can oxidize gallic acid and rutine in a region of potential close to that oxidation of sulfite takes place (results not shown). These results indicate that these polyphenols can act as interfering but these results can be avoided if a membrane contactor for the samples is used $^{25-27}$.

Stability of CPE and CILEs

Finally, we proved the stability of all the CILEs excepting CILE/ $\mathrm{OCH}_{3}$ recording their current response in the presence of $2 \mathrm{mM}$ of sulfite during 100 cycles. After obtaining a stable response, the current of all the electrodes measured was almost constant diminishing less than $5 \%$ during the 100 potentiodynamic cycles. On the other hand, we proved the stability of the studied CILEs obtaining its stable response during ten cycles. Then, they were washed and exposed to air during two days. After this time, they were measured in a fresh solution of $2 \mathrm{mM}$ of sulfite obtaining the same result compared to the previous measure. We did the same experiments ten times for each electrode obtaining in each case, a very high stability in current (variations lower than 5\%) showing that the electrodes can be used for removal of sulfite from wastewaters.

\section{CONCLUSIONS}

The modification of a carbon paste electrode with ionic liquids derived from N-octyl-pyridinium hexafluorophosphate generates electrodes that are more active towards the sulfite oxidation compared to a conventional carbon paste electrode (CPE). Compared to $\mathrm{CPE}$, a high shift in the potential required to the oxidation takes place when CILEs are the working electrodes. However the electron donating or withdrawing nature of the substituent of the cation of the ionic liquid does not influence the oxidation potentials. The mesomeric or inductive effects of the substituents determine the potential of the oxidation peak, indicating that inductive-substituents-CILEs require less energy to promote the oxidation of sulfite. On the other hand, the amperometry study of sulfite oxidation shows that two of CILE electrodes could be used in analysis of pretreated wines or vinegars because their sensibility. They are the CILE/CH and CILE/OPy. All the CILEs excepting CILE/OCH 3 can be used for removal of sulfite from wastewater due to their stability.

\section{ACKNOWLEDGEMENTS}

Authors thank financial support from Fondecyt 1160324 project, DictyUsach and Project RC 130006, CILIS, granted by Fondo de Innovación para la Competitividad, del Ministerio de Economía, Fomento y Turismo, Chile

\section{REFERENCES}

1.- F. Faridbod, M. Reza, P. Norouzi, S. Riahi, H. Rashedi in Application of room temperature ionic liquids in electrochemical sensors and biosensors. Ionic Liquids: Applications and Perspectives. 2011, pp.643-658.

2.- A. Mehrkesh, A. Karunanithi, Fluid Phase Equilib. 427,498 (2016)

3.- T.Tsuda, C. Hussey in Electrochemical Applications of Room-Temperature Ionic Liquids. Electrochem. Soc. Interface. 2007 pp. 42-49.

4.- A. Franco-Vega, E. Palou, N. Ramirez-Corona, A. Lopez-Malo in Líquidos iónicos: una alternativa verde para procesos de extracción en la industria de alimentos. Temas selectos de ingeniería de alimentos. 2014, vol. 1, pp.15-26.

5.- S. Vishwakarma IJBSAC.1, 1, (2014)

6.- P. Hapiot, C. Lagrost, Chem. Rev. 108, 2238, (2008)

7.- X. Cao, X. He, J. Wang, H. Liu, S. Röser, B. Razaei Rad, M. Evertz, B. Streipert, J. Li, R. Wagner, M. Winter, I. Cekic-Laskovic. ACS App. Mater. Interfaces. 8, 25971 (2016)

8.- M.Opallo, A. Lesniewski, J. Electroanal. Chem. 656, 2, (2011)

9.- M.Shiddiky, A Torriero, Biosens. Bioelectron. 26,1775, (2011)

10.- N. Maleki, A. Safavi, ; F. Tajabadi, Anal. Chem. 78, 3820, (2006)

11.- M. Shamsipur, A. Pashabadi, A. Taherpour, B. Hemmateenejad, T. Khosousi, M. Hadi Parvin, J. Electroanal. Chem. 778, 116 (2016)

12.- M. Godindhan, A. Chen, Microchim. Acta. 183, 2879 (2016).

13.- A. Safavi, N. Maleki, F. Honarasa, F. Tajabadi, F. Sedaghatpour, Electroanal.19, 582, (2007)

14.- A. Safavi, N. Maleki, O. Moradlou, F. Tajabadi, Anal. Biochem. 359, 224, (2006).

15.- E. Bordeu and J. Scarpa. Análisis Químico del vino. Ediciones Universidad Católica de Chile, Santiago 2000.

16.- F. Zamora in Anhídrido sulfuroso; Algunas reflexiones sobre este aditivo. Revista enólogos. 2005, no. 38. pp. 28-31.

17.- R. Jackson in Wine science principles and applications. Elsevier, San Diego, 2014.

18.- Y.Yang, Y. Yan, X. Chen, W. Zhai, Y. Xu, Y. Liu, Electrocatal. 5, 344 (2014)

19.- E. Silva, R. Takeuchi, A. Santos. Food Chem. 173, 763 (2015)

20.- B. Devadas, M. Sivakumar, S. Ming Chen, S. Cheemalapati. Electrochim. Acta, 176, 350 (2015)

21.- L. Xu, F. Guo, Y. You, J. Hu, Y. Miao, Z. Wu, L. Wang. Int. J. Electrochem. Sci. 11, 4586 (2016).

22.- W. Syrosee, K. Ponlakhet, S. Charaim, P. Jarujamrus, M. Amatatongchai, Talanta, 156-157,154 (2016)

23.- D. Fang, J. Cheng, K. Gong, Q. Shi, L. Zhou, Z. Liu, J. Fluorine Chem. 129, 108, (2008).

24.- U. Domańska, K. Skiba, M. Zawadzki, K. Paduszyńsky, M. Królikowski. J. Chem. Thermodyn. 56, 53, (2013).

25.- R. Arce, MJ. Aguirre, J. Romero. Int. J. Electrochem. Sci. 9, 7916 (2014)

26.- R. Arce, J. Romero, M J. Aguirre. J. Appl. Electrochem. 44, 1361 (2014)

27.- R. Arce, C. Baéz, J. P. Muena, M J. Aguirre, J. Romero. J. Chil. Chem. Soc. 61, 3014, (2016)

28.- J.C. Miller, J.N. Miller in Estadística para química analítica. EUA Eds. Addison Wesley, Iberoamericana, 1988.

29.- Ley 18.455, Decreto 78, Normas sobre producción, elaboración y comercialización de alcoholes etílicos, bebidas alcohólicas y vinagres. 